\title{
EDITORIAL
}

\section{COVID-19: Rebooting pharmacy education in resource-limited settings}

\author{
Jennie Lates, Dan Kibuule \\ School of Pharmacy, Faculty of Health Sciences, University of Namibia, Namibia
}

\author{
Correspondence \\ Jennie Lates \\ School of Pharmacy \\ Hage Geingob Campus \\ University of Namibia \\ Private Bag 13301 \\ Windhoek \\ Namibia \\ jlates@unam.na
}

\begin{abstract}
Globally, the COVID-19 pandemic has aggravated inequalities in access to quality pharmacy education, particularly in resource-limited settings in Africa (Engle, 2020; Fuller et al., 2020). This is a serious concern for Africa especially, given that sub-Saharan Africa ranks lowest on the global pharmaceutical workforce index and has a disproportionately high burden of infectious and non-communicable diseases, combined with weak health systems (World Health Organisation [WHO], 2013; Bates et al., 2018).
\end{abstract}

The rebooting of pharmacy education in resource-limited settings following the COVID-19 pandemic requires urgent re-alignment to FIP's Workforce Development Goals (International Pharmaceutical Federation [FIP], 2020). Immediate attention must be paid to: Goal 1, to increase academic capacity for blended learning, Goal 3, quality assurance through implementation of quality assurance guidelines and systems for eLearning; and Goal 8, fostering collaborative education with local stakeholders and international partners. This editorial reflects a success story, as well as challenges and strategies employed by Namibia's School of Pharmacy to sustain the Bachelor of Pharmacy programme during the COVID-19 pandemic.

Namibia, a middle-income country in sub-Saharan Africa, has one of the highest income inequalities in the world attributed to apartheid that negatively affected socioeconomic, health and education systems (Makamani, 2018). Until the launch of School of Pharmacy in 2012, Namibia relied on foreign-trained workforce to drive the pharmaceutical sector; this is costly and unsustainable (McQuide, Kolehmainen-Aitken, \& Forster, 2013; Rennie et al., 2019).
The University of Namibia's (UNAM) School of Pharmacy, aims to strengthen pharmaceutical workforce and systems and reduce inequalities in healthcare. Through collaborative networks and the implementation of work-integrated and internship support programmes, the School has significantly boosted the pharmaceutical workforce indicators for pharmaceutical technicians, clinical pharmacists and pharmacists in Namibia (Rudall, Kalemeera, \& Rennie, 2015; Rennie et al., 2018). The COVID-19 pandemic however threatens the sustainability of and equitable access to quality pharmacy education in Namibia and other resource-limited countries, given that COVID-19 has aggravated socio-economic disparities between students and institutions (Dube, 2020). The UNAM full time Bachelor of Pharmacy (B.Pharm.) programme was more affected than the work-integrated programmes, i.e. Diploma in Pharmacy and the Masters in Clinical Pharmacy. Consequently, this editorial calls for rethinking the design and implementation of pharmacy education in the era of epidemics, to sustain quality training of competent workforce and mitigate inequalities in healthcare delivery, particularly in resource-limited settings. 
The COVID-19-related state of emergency lockdown imposed throughout Namibia in March 2020 significantly contained the disease with only 16 imported cases reported in March and April 2020, with zero community transmission (Lendelvo, Pinto, \& Sullivan, 2020; NamibLII, 2020; Ogunleye et al., 2020). The state of emergency interventions included a national lockdown for six weeks, further regional lockdowns in Erongo and Khomas regions, the epicentres of the disease, and the enforcement of adherence to government COVID-19 protocols in public domains. However, since the end of the initial lockdown in May 2020, community transmission has increased the number of cases to 12675 (at 26 October), the highest per capita in Africa (Gayawan et al., 2020).

The lockdowns were essential to slow the spread of COVID-19, however they severely disrupted academic and economic activities, including the importation of essential pharmaceuticals and supplies (Evelina, Samuel, \& Homateni, 2020). Consequently, UNAM migrated all teaching, learning and assessment activities online, and expedited review of relevant policies, to ensure quality of online education. The move to online education was not without challenges; most institutions were not ready to scale up eLearning, mainly due to limited ICT infrastructure countrywide to sustain remote training. UNAM scaled up eLearning through Moodle, a learning management system first implemented by the University in 2015 to support its distance programmes. Moodle has been a critical tool in the successful implementation of work-integrated pharmacy education, for the Masters in Clinical Pharmacy and the Diploma in Pharmacy (Kibuule et al., 2017; Rennie et al., 2018; Hachey et al., 2019).

Due to the COVID-19 pandemic, the School of Pharmacy scaled up online pharmacy education from about $10 \%$ of B.Pharm. modules $(n=6 / 58)$ to all modules under the B.Pharm. programme. Staff training before lockdown on Moodle and video capture software, Panopto, was enhanced through support from a coordinator at the School and UNAM's Centre for Open, Distance and e-Learning. In late April, to augment government's efforts towards COVID-19 control, UNAM replaced traditional face-to-face examinations with online assessments, using questions from moderated examination papers.

A rapid survey, conducted two weeks after the move to online learning, showed that although $98 \%$ of B.Pharm. students were linked to the Moodle platform, almost a third (29\%) were not able to access Moodle all the time, mainly due to data and internet connectivity challenges and many had to pay for data connection to access online resources. The poor connectivity and out of pocket expenses disadvantaged several students access to learning resources, affecting their performance. Kibuule et al., describe the success, challenges and the competence implications of online migration of pharmacy education in Namibia (Kibuule et al., in press). Challenges mainly pertain to inequitable access to devices and infrastructure for online learning, the applicability of online learning in clinical, practical and experiential training, quality assurance of online assessment, limited learning support and administration of teaching and learning on the various platforms used.

The decision to replace traditional examinations with online assessments raised concerns regarding the reliability and validity of formative assessment, given that on-line assessments are largely open book and may not accurately assess the students' knowledge and competences. Mavu et al. describe ten key elements for building resilience into pharmacy education, to overcome challenges posed by the COVID-19 pandemic (Mavu et al., in press.). The pandemic also had a significant impact on the mobility of visiting lecturers that support the clinical training programmes, as well as student academic and research mentorship (Hachey et al., 2020). For clinical pharmacy training, faculty shifted to use of mock patient cases or faculty selected cases, to minimise student contact with patients in health facilities.

The pandemic impeded efforts to internationalise pharmacy education through a three week industrial experiential learning experience at pharmaceutical manufacturing facilities in Southern and East Africa. However, this provided an opportunity to recreate the industrial placements in an emergency setting, such as COVID-19. Mavu et al. (2020) describe a training model for up-skilling pharmacy graduates in compounding of quality assured COVID-19 essential medicines; this model may be adopted for industrial experiential training in resourcelimited settings. In this training model, a readiness programme for pharmacy graduates to compound, quality assure and regulate (register, inspect, and provide therapeutic information) COVID-19 essential medicines is described (Mavu et al., 2020).

The switch from conventional face-to-face curriculum to $100 \%$ online pharmacy education impacted the effectiveness of teaching delivery. Several of the School faculty did not fully comprehend the Moodle platform. This led to lecturers adopting several different mechanisms of teaching, resulting in a multiplicity of teaching modes being implemented, including emailing, WhatsApp, Dropbox and Zoom. 
Students adopted several coping mechanisms, including virtual student learning support WhatsApp groups, travelling to nearest towns or relatives' workplaces to access stable internet and collaborative efforts to complete assessments. Nevertheless, some students were unable to complete learning, particularly students in remote areas and those from disadvantaged backgrounds, mainly due to lack of devices and/or internet. To address this, UNAM implemented a two-month face-to-face intervention remedial period (June - July 2020) for students who were unable to complete learning due to connectivity challenges, as well as to implement experiential and practical pharmacy training. Whilst online learning can replace theoretical training, there are quality assurance concerns regarding its use in place of practical, practice and clinical pharmacy education. This has an impact on the actual contact hours of learning and credits towards meeting the curriculum competences. However, the School has maintained close contact with the professional accreditation body and has received approval for the implemented curriculum, due to the steps taken to assure quality at all stages.

In conclusion, we wish to highlight the urgent need to strengthen pharmacy education in resource-limited settings, by adopting a curriculum aligned to the fourth industrial revolution. Schools of Pharmacy have a duty to optimise their training programmes, through integrating technology and innovations in learning and teaching. In addition, there is a need to ensure students access ICT equipment, stable internet and remote online support, for sustainability of quality online pharmacy education. This will secure equitable access to training for future pharmacy personnel in this current, uncertain world.

\section{References}

Bates, I., John, C., Seegobin, P., \& Bruno, A. (2018). An analysis of the global pharmacy workforce capacity trends from 2006 to 2012. Human Resources for Health. https://doi.org/10.1186/ $\underline{\text { s12960-018-0267-y }}$

Dube, B. (2020). Rural online learning in the context of COVID 19 in South Africa: Evoking an inclusive education approach. Multidisciplinary Journal of Educational Research, 10(2). https://doi.org/10.17583/remie.2020.5607

Engle, J.P. (2020). Assuring Quality in Pharmacy Education During a Time of Crisis. American Journal of Pharmaceutical Education, 84(6). https://doi.org/10.5688/ajpe8135

Evelina, J., Samuel, N., \& Homateni, J.L. (2020). Estimating the economic impact of COVID-19: A case study of Namibia. MPRA, Paper No. 99641. Available at: https://mpra.ub.uni-muenchen.de/ 99641/
Fuller, K.A., Heldenbrand, S.D., Smith, M.D., \& Malcom, D.R. (2020). A Paradigm Shift in US Experiential Pharmacy Education Accelerated by the COVID-19 Pandemic. American Journal of Pharmaceutical Education, 84(6), https://doi.org/10.5688/ajpe $\underline{8149}$

Gayawan, E., Awe, O.O., Oseni, B.M., Uzochukwu, I.C., Adekunle, A., Samuel, G., et al. (2020). The spatio-temporal epidemic dynamics of COVID-19 outbreak in Africa. Epidemiology and Infection, 148, E212. https://doi.org/10.1017/S0950268820001983

Hachey, D., Jonkman, L., Corkhill, N., Rennie, T., Lates, J., \& Mubita, M. (2020). The role of visiting faculty on the training of clinical pharmacists in Namibia: A qualitative study. Journal of the American College of Clinical Pharmacy, 3(1). https://doi.org/ $\underline{10.1002 / j a c 5.1122}$

FIP [International Pharmaceutical Federation]. (2020). The FIP Development Goals. International Pharmaceutical Federation The Hague. Available at: https://www.fip.org/file/4793

Kibuule, D., Lates, J., Ishola, A., Hango, E., Kalemeera, F., Knott, M., Mavu, D., Singu, B., Brinkmann, I., \& Rennie, T.W. (2020). Migration to online pharmacy education in Namibia: successes, challenges and competence implications. Pharmacy Education (in press)

Kibuule, D., Lates, J., Kagoya, H.R., Bayobuya, P., Niaz, Q., \& Rennie, T.W. (2017). Cost-effective model for monitoring medicine use in Namibia: Outcomes and implications. African Evaluation Journal, 5(2). https://doi.org/10.4102/aej.v5i2.213

Lendelvo, S., Pinto, M., \& Sullivan, S. (2020). A perfect storm? The impact of COVID-19 on community-based conservation in Namibia. Namibian Journal of Environment, 4 (2020)

Makamani, R. (2018). HARAMBEE PROSPERITY PLAN: A Corpus-Driven Rhetorical and Postcolonial Reading. African Journal of Rhetoric, 10(1), 122 - 141. https://journals.co.za/content/ journal/10520/EJC-11a5aa1af8

Mavu, D., Mubita, M.,Hango, E., Lates, J., \& Rennie, T.W. (2020). COVID-19 resilient pharmacy education: a grassroots work-integrated programme to stregthen pharmaceutical workforce in Namibia. Pharmacy Education (in press)

Mavu, D., Mubita, M., Niaz, Q., Lusepani, M., Nowaseb, S., Enkara, T., et al. (2020). Emergency compounding of COVID-19 medicines: a readiness program to upskill pharmacy graduates in Namibia. Pharmacy Education (under review)

McQuide, P.A., Kolehmainen-Aitken, R.L., \& Forster, N. (2013). Applying the workload indicators of staffing need (WISN) method in Namibia: Challenges and implications for human resources for health policy. Human Resources for Health, 11(1). https://doi.org/ $\underline{10.1186 / 1478-4491-11-64}$

NamibLII. (2020). Namibia-covid-19. Available at: https://namiblii. org/namibia-covid-19

Ogunleye, O. O., Basu, D., Mueller, D., Sneddon, J., Seaton, R. A., Yinka-Ogunleye, A. F., et al. (2020). Response to the Novel Corona Virus (COVID-19) Pandemic Across Africa: Successes, Challenges, and Implications for the Future. Frontiers in Pharmacology. https://doi.org/10.3389/fphar.2020.01205 
Rennie, T., Nangombe, V., Mangombe, T., Kibuule, D., \& Hunter, C. J. (2019). Health workforce planning in Namibia: assessing a pilot workforce survey of pharmacists. International Journal of Pharmacy Practice, 27(6), 565-574. https://doi.org/10.1111/ijpp. $\underline{12547}$

Rennie, T.W., Coetzee, N., Hunter, C. J., Jonkman, L., Kalemeera, F., Kibuule, D., et al. (2018). Short report: Piloting a new pharmacy internship support programme in Namibia. Pharmacy Education, 18(1), 88-90

Rudall, N., Kalemeera, F., \& Rennie, T. (2015). Implementing clinical pharmacy within undergraduate teaching in Namibia. International Journal of Clinical Pharmacy, 37(3), 427-429. https://doi.org/10.1007/s11096-015-0082-7

WHO [World Health Organization]. (2013). WHO and Global Health Workforce Alliance. A universal truth: no health without a workforce. Geneva: World Health Organisation (WHO) and Global Health Workforce Alliance, 2013. Available at: http://www. who.int/workforcealliance/knowledge/resources/GHWA-a univer sal truth report.pdf?ua $=1$ 